\title{
ANALYSIS OF INCIDENCE, ETIOLOGY AND RISK FACTORS ASSOCIATED IN ACUTE BURN INJURY IN ADULTS AT ANMMCH, GAYA, BIHAR
}

\section{Surgery \\ Dr. Kishore Kumar Sinha

Dr. Abhai Kumar
Jha Suman*

Dr. Alok Kumar
M.S. (Gen. Surg.), Associate Professor, Department of surgery, Anugrah Narayan Magadh Medical College and Hospital, Gaya, Bihar.

M.S. (Gen. Surg.), Associate Professor, Department of surgery, Anugrah Narayan Magadh Medical College and Hospital, Gaya, Bihar. *Corresponding Author

M.S. (Gen. Surg.), Senior Resident, Department of surgery, Anugrah Narayan Magadh Medical College and Hospital, Gaya, Bihar.

Young Scientist (DST), Institute of Post-Graduate Medical Education and Research,

A.J.C. Bose Road, Kolkata-700020, West Bengal, India

\section{ABSTRACT}

Introduction: Burn injuries have major health problem because of its high, morbidity, disability andmortality in young and middle-aged people Burn injuries also have social problems associated with it. It may be associated with accidental, suicidal or homicidal causes. Despite of such importance of burn injuries from clinical and social point of view, there is scarcity of research on burn injuries in India. Thus we tried to highlight our observations in this study which had been undertaken to find out the causes of burn and it's clinical profile and treatment outcome of burn patients in the our Institute.

Material methods: This observational study was conducted from August 2016 to March 2020 in patients ofburn injury who were admitted in surgery wardsand burn ICU of Anugrah Narayan Magadh Medical College \& Hospital, Gaya, Bihar. We have studied 226 burn patients who admitted in our general surgical units and burn icu of our Institute. Burns patients who are above 18 years and both sexes were including in the study.

Results: A total of 226 patients had burns injuries. 162 were male and 64 female in the ratio of M: F-2.53:1.Males were mostly affected (71.68\%) in comparison to females. Most of the burn patients were in the age group of 21-30 years in this studied.i.e.42.02\%. Lesser patients were seen in age group $50-75$. As regard the causes, duringthe house hold activities has maximum number of patients as shown and electricity is causing second highest cases (26.99\%), less number of patients are suicidal (3.53) and unknown etiology is seen in seven cases.

Conclusion: Burn injury prevention is very difficult task, but to avoid the significant morbidity andmortality following the burn injury. We have to take every measures to control its incidence. A coordinated and dedicated approach by social workers, medical and paramedical personnel and administrators can only minimize the incidence of burn injury in India.

\section{KEYWORDS}

preventive measures, incidence, causes, types of burn, house hold activities

\section{INTRODUCTION}

Burns injuries are very serious and impair a patient's emotional wellbeing and influence his quality of life. The World Health Organization estimates that more than 300,000 people die annually from fire-related burns worldwide. World Health Organisation (WHO) has also classified burn injuries caused by fire, flames, smoke, hot substances, electric current, lightening, and exposure to corrosive substances. Burn injuries continue to contribute significantly to the global burden of disease. They account for over 310,000 fire-related unintentional deaths each year, largely among children and young adults. According to $\mathrm{WHO}$, the incidence rate in low- and middle-income countries is 1.3 compared to 0.14 per 100,000 population in high-income countries. Over ninety five percent of fatal burn injuries occur in poor countries.

Recent studies on injuries show that burns are one of the leading causes of unintentional home-related injuries in, accounting for $40 \%$ of those injuries across all age groups. A high proportion of these burn injuries have been reported among females. It is expected that a person can suffer from burns during his lifetime is $1 \%$. After considering all these factors, the study was conducted with objectives to study the sociodemographic factors of burn patients in northern region of India, to find out the causes of burn injury and its outcome in patients admitted in our premier institute.

\section{MATERIALS AND METHODS}

This observational study was conducted in between August 2016 to March 2020 in patients of burn injury who were admitted in general surgical wardsand burn ICU of Anugrah Narayan Magadh Medical College \& Hospital, Gaya, Bihar. In this study we have tried to emphasize the importance of prevalence of burn injury, its various types. Modes of occurrence, risk factors and to find out the preventive measures. We have studied 226 burn patients who admitted in our general surgical units of our Institute. Burns patients who are above 18 years and both sexes were including in the study.

The information obtained were documented as name, age, sex, place of incidence, injury -related data, including the etiology of burn injuries, area of the burn, injured anatomic locations, and inhalation injury; The etiology of burn injuries included flame burn, scald burn, contact burn, electrical burn. All patients were initially resuscitated with either normal saline or Ringer's lactate Superficial were covered with silver sulphadiazine until healing occurs by re-epithelisation. most wounds of the trunk and extremities were dressed until eschar separates before the skin was grafted.

\section{RESULTS}

A total of 226 studied patients had burns injuries. Out of 226, there were 162 male and 64 female in the ratio of M: F-2.53: 1. Males were mostly commonly affected $(71.68 \%)$ in comparison to females. Most of the burn patients were in the age group of $21-30$ years. i. e. $42.02 \%$. The number of burn patient was least in the age group 51- 60 years i.e. $4.47 \%$. This distribution is presented in Table 1 .

Table 1: Distribution of cases with their age group in years

\begin{tabular}{|c|c|c|c|c|c|c|}
\hline Age group & Male & \% age & female & \% age & Total & $\%$ age \\
\hline$<20$ & 26 & 11.50 & 13 & 5.75 & 39 & 17.25 \\
\hline $21-30$ & 75 & 33.18 & 20 & 8.84 & 95 & 42.02 \\
\hline $31-40$ & 29 & 12.83 & 12 & 5.30 & 41 & 18.13 \\
\hline $41-50$ & 18 & 7.96 & 9 & 3.98 & 27 & 11.94 \\
\hline $51-60$ & 7 & 3.09 & 3 & 1.38 & 10 & 4.47 \\
\hline$>60$ & 7 & 3.09 & 7 & 3.09 & 14 & 6.18 \\
\hline All & 162 & 71.68 & 64 & 28.31 & 226 & 100 \\
\hline
\end{tabular}

Maximum patients have (81) $25-50 \%$ age of burns as per table 2. Least patients are seen in 50-75 percentage of burn.

Table 2: Distribution of cases with percentage of burn

\begin{tabular}{|c|c|c|}
\hline \% age of burn & Number of patients & \% age \\
\hline$<25$ & 80 & 35.39 \\
\hline $25-50$ & 81 & 35.84 \\
\hline $50-75$ & 31 & 13.71 \\
\hline$>75$ & 34 & 15.04 \\
\hline total & 226 & 100 \\
\hline
\end{tabular}


A lot of accidents occurred at home and in the kitchen. Pump stoves (Kerosene) are used commonly for cooking purposes. The mechanisms most commonly found in these injuries were due to explosion of stoves after excessive pumping, filling of fuel while the stove was on. Gas cylinder related injuries occurred in houses and at work places.

Table 3: Distribution of case with their causes

\begin{tabular}{|c|c|c|}
\hline Causes & No. & \% age \\
\hline House hold activities & 121 & 53.53 \\
\hline Electric current & 61 & 26.99 \\
\hline Work place & 16 & 7.07 \\
\hline Suicidal & 8 & 3.53 \\
\hline Hot liquid & 13 & 5.75 \\
\hline unknown & 7 & 3.09 \\
\hline & 226 & 100 \\
\hline
\end{tabular}

As per table no.3, maximum burns are due to activities at home seen in $53.53 \%$. Electricity is causing second highest cases $(26.99 \%)$, less number of patients are suicidal (3.53) and unknown etiology seen in seven patients.

These type of accidents occurred when someone forgot to switch off the cylinder valve, use of damaged pipe leading to leakage and the explosion following lighting in a closed kitchen. Oil lamps ('kupi'), candles and hurricane-lanterns, diyas (Clay baked earthen oil lamps) were also responsible to number of burns. All accidents were happened due to human mistake.

Irrespective of fuel/burners, both flame burns and scald occurred in kitchen.

\section{DISCUSSION}

Despite tremendous development in medical science, burn injuries still represent one of the most leading causes of death, morbidity and also has a long-term social impact in low- and middle income countries. The International Society for Burn Injuries (ISBI) defined a burn is a type of injury that occurs in different layers of cells in the skin, and cause can be, contact burns by hot liquids or due to flames. Skin by electricity or chemicals, ultraviolet radiation, radioactivity, as well as injuries caused by smoke inhalation, resulting respiratory damage from, are also being considered burn injury.

Although $>90 \%$ of all burns are preventable, but remains a major public health problem.7 The etiology and nature of burn injuries varies significantly by different communities and social groups. But the modes of injuries can be due to accidental, suicidal and homicidal. Depending on the extent and severity of burns, and the availability and accessibility to health care, the impact of burns varies from superficial burns and scalds to the damage of the internal body organs. The maximum numbers of patients $(42.02 \%)$ were in the age group of 21 to 30 years, which indicate greater exposure to burn agents in these age groups than in any other age group. These results are consistent with the other previous studies.

The study done by Attia AF et al. and Singh MV et al. shows that; about $66 \%$ of the patients were in the age group of 21-50 years and is the most productive age group in our country and more susceptible to injuries both in home and in workplace. This type of age distribution is similar to other studies in India and outside. Although of prevention of burns has increased now, but still many people suffered burn injuries yearly. 9 Severe burns can lead to extremely serious deformity, disability, or even death. 12 Almost $80 \%$ of the patients were between 18 and 40 years old, which is similar to other studies. Now study, $59 \%$ of the burn injury admissions were males, showing a peak between 21 to 30 years (33.18\%), followed by 31 to 40 years (12. 83\%). In contrast, Ahuja and Bhattacharya (2002) reported higher admissions of women with burns $(58 \%)$. Gender differences play a significant role in the risk of burn injuries, across a spectrum with a predominance of women injured in fires from cooking and heating fuels in the developing world. Moreover in the developing country like India, females are married earlier than males in the family and are more exposed to social and family stress. In this study $35.84 \%$ patients sustained major burns injuries involving $25-50 \%$ of body surface areas and $28.75 \%$ of patients have involvement of more than fifty percent of surface areas, which is consistent with other studies.

Kumar (2000) observed that among those with burn injuries, 37\% had an involvement of $>20 \%$ of the body surface area. In our study, $53.53 \%$ patients were suffering from burns by activities in house hold, $26.99 \%$ were suffering from electric current injury $7.07 \%$ of patients were from burns at work place like factory workers welding shops using LPG cylinders and only $3.09 \%$ were suffering from burns of unknown aetiology-some patients have history of psychiatric illness. In a study done by Gupta A et al, $72 \%$ patients got thermal burns, $7 \%$ got scalds and $17 \%$ got electric burns. Also study conducted by Nnabuko REE et al reported that the most frequently affected age group was in the second decade of life (33.3\%). Contact with live wire or contact with an object that was in contact with a live wire (secondary contact) accounted for 43 of 84 cases $(51 \%)$. Home was the most common location where injury occurred (51.2\%).

Patients with severe burns often need long-term hospitalization and undergo multiple surgical procedures, and some require readmission for reconstructive surgery. The impact of physical disfigurement and pain due to severe burns are far-reaching, and the psychological impairments can last a lifetime. In developing nations, burn continues to be endemic because of large scale use of unsafe stoves and fuel Majority of burns were caused by flame, with kerosene. This is probably due to its availability and common use as domestic fuels. In relation to causes of burn most of patients had accidental burns while $3.53 \%$ sustained suicidal and $5.75 \%$ had burns by hot liquid. burns. Our observations conform to published reports. Some females do not reveal the true cause of burn but instead blame it on some accidental reason as cause of their burns. It may be due to pressure of relatives and because of anxiety, patients initially confess to have sustained accidental burns. However, these medicolegal aspects are beyond the scope of the present study. In the present study it was observed that the majority of burns admitted to hospital occurred at home. These observations are consistent with those reported by others.

The problems of burn injuries is more severe developing countries, due to the reason that burn patients requires more specialized units are expensive and they are not always available. Public awareness through different communication medias and education through schools colleges could be provided about burn-related safety measures. Good awareness on safer first-aid practices such as applying cold water soon after sustaining burns is essential. Precautions and safety measures taken during food preparation care of electricity wires and in the working places like factories welding shops could help to prevent burns. There should be availability of Up To Date burn care centers in all public institutions as near to the place of accident as possible.

\section{CONCLUSION}

Analyzing the epidemiological aspects of burns, there is need for some specific suggestions that serves to provide the best service to relieve their pain and avoid the significant morbidity and mortality following injury. Some effective national programs should be made for strengthening of health promotion, and protection poor persons. A joint approach should be made among well dedicated social workers, medical and paramedical staff and government officials to minimize the incidence of burn. There is need to develop cost-effective, according to cultural need, and sustainable interventions for burn injury patients and its prevention and control. The interventions can be Education the society, engineering the burn programs, their enforcement in dedicated manner, and latest facilities for Emergency burn care.

\section{REFERENCES}

1. Ahn CS, Maitz PK. The true cost of burn. Burns. 2012; 38:967-74

Ahuja R, Bhattacharya S. An analysis of 11,196 burns admissions and evaluation of Ahuja R, Bhattacharya S. An analysis of 11,196 burns admi
conservative management techniques. Burns. 2002; 28:555-61

3. Attia A, Sherif A, Mandil A, Massoud N, Arafa M, Mervat W et al . Epidemiological and sociocultural study of burn patients in Alexandria, Egypt. East Mediterr Health J. 1997; 3:452-61

4. Attia AF, Sherif AA, Mandil AM, Massoud NM, Arafa MA, Mervat W. Epidemiological and sociocultural study of burn patients in Alexandria, Egypt. East Mediterr Health J. 1997; 3:452-46

5. Fan $\mathrm{X}, \mathrm{Ma} \mathrm{B}, \mathrm{Zeng} \mathrm{D}$, Fang $\mathrm{X}, \mathrm{LiH}, \mathrm{Xiao} \mathrm{S}$, et al Burns in a major burns center in East China from 2005 to 2014: incidence and outcome Burns 2017; 43:1586-95.

6. Gupta A, Uppal S, Garg R, Gupta A, Pal R. A clinico-epidemiologic study of 892 patient with burn injuries at a tertiary care hospital in Punjab, India. J Emerg Trauma Shock. 2011;4:7-11

7. Gupta M, Gupta C, Yaduwanshi R. Burn epidemiology: The pink city scene. Burns $1993 ; 19: 47-51$

8. Han TH, Kim JH, Yang MS, Han KW, Han SH, Jung JA etal. A retrospective analysis of 19,157 burns patients: 18-year experience from Hallym Burn Center in Seoul, Korea. Burns. 2005; 31:465-70.

9. International Statistical Classification of Diseases and Related Health Problems, 10th Revision. ICD-10 Version: 2006. (Online) (Cited 2012 June 4). Available from URL: http://www.who.int/classifications/apps/icd/icd10online/

10. Jayaraman V, Ramakrishnan K, Davies M. Burns in Madras, India: an analysis of 1368 
patients in 1 year. Burns 1993; 19(4):339-44

Kumar P, Chirayil P, Chittoria R. Ten years of epidemiological study of pediatric burns in Manipal, India. Burns. 2000; 26:261-4.

12. Nnabuko REE, Ogbonnaya IS, Otene CI, Ogbonna U, Amanari OC, Opara KO. Burn Injuries in Enugu, Nigeria-Aetiology and Prevention. A Six-year Retrospective Review (January 2000 - December 2005). Ann Burns Fire Disasters 2009; 22(1):40-43.

13. Organization WH. A WHO plan for burn prevention and care. Bull World Health Organ. 2008; 87:802-3.

14. Othman N, Kendrick D. Epidemiology of burn injuries in the East Mediterranean Region: a systematic review. BMC Public Health. 2010; 10:83. doi: 10.1186/14712458-10-83.

15. Sharma B, Dasari H, Sharma V, Vij K. Kitchen accidents vis-à-vis dowry death. Burns. 2002; $28: 250-53$

16. Sharma P, Bang RL, Ghoneim IE, Bang S, Sharma P, Ebrahim M. Predicting factors influencing the fatal outcome of burns in Kuwait. Burns. 2005; 31:188-92.

17. Singh M, Ganguli S, Aiyanna B. A study of epidemiological aspects of burn injuries. Med J Armed Forces India 1996; 52:229-32.

18. Singh MV, Ganguli SK, Aiyanna BM. A study of epidemiological aspects of burn injuries. Med J Armed Forces India. 1996; 52:229-232.

19. Smolle C, Cambiaso-Daniel J, Forbes AA, Wurzer P, Hundeshagen G, Branski LK et al Recent trends in burn epidemiology worldwide: a systematic review. Burns. 2017, 43:249-57.

20. World Health Organization. Violence and Injury Prevention: Burns. (Online), 2011. Available from URL:http://www.who.int/violence_injury prevention/ other injury/bu rns/en/index.html. 